\title{
Age Group Identity and Political Participation
}

\author{
Samuel Trachtman, UC Berkeley \\ Sarah F. Anzia, UC Berkeley \\ Charlotte Hill, UC Berkeley
}

\begin{abstract}
Young adults are underrepresented in American politics, but political scientists have devoted little attention to age bias in political participation and public policy. Drawing on arguments that groups vary in their cohesiveness, and that groups with stronger shared identity participate in politics at higher rates, we explore the relationship between age identity and political participation. Using data from a survey of a nationally-representative sample of adults, we measure how strongly citizens identify with others in their age group. We find that young adults do tend to have weaker age identity than senior citizens, but also that their average age identity is as strong as their political party identity. Second, we explore whether age identity is associated with two forms of political participation: voting and participating in protests related to climate change. We find that age identity is a strong predictor of both forms of political participation, especially for young adults.
\end{abstract}

This paper was previously presented at the annual meeting of the Southern Political Science Association, January 6-9, 2021. The survey for this study was funded by the Berkeley Institute for Young Americans. The authors thank the Institute for its support and are grateful for helpful feedback from Elizabeth Mitchell and Eric Schickler. 
Political observers often lament that American democracy works better for older citizens than younger citizens (e.g., Noah 2019), but American politics research has yet to devote significant attention to age bias in political participation, representation, and public policy.

For example, young adults vote at much lower rates than older citizens (Rosenstone and Hansen 1993, Wolfinger and Rosenstone 1980), but the reasons for that are not fully understood. Research on political participation mostly treats age as a control variable (see Verba and Nie 1972, Verba et al. 1995). Some argue that young people haven't yet had the life experiences that lead them to care about politics (Beck and Jennings 1982, Strate et al. 1989), but Holbein and Hillygus (2020) show that many young adults are actually quite interested in politics. A small group of political scientists has started to bring fresh attention to this question, showing how electoral institutions can disproportionately affect the turnout of young people (Grumbach and Hill 2021, Hill 2020, Holbein and Hillygus 2020), but as of now, the American politics literature still lacks a thorough account of why participation varies so dramatically by age.

There are also indicators that politics and public policy are more favorable to older citizens than younger citizens. The average age of U.S. elected officials is rising (Noah 2019). The federal government has failed to take meaningful steps to slow climate change, and younger generations will bear the brunt of that inaction. Homeownership remains out of reach for many young people, in large part because of restrictive zoning regulations and public meetings that amplify older voices (Einstein et al. 2019). And at all levels of government, revenue limits combined with spending growth on Social Security, major government healthcare programs, and public employee retirement benefits are reducing government capacity in other areas, such as programs for families and children (Anzia forthcoming, Congressional Budget Office 2000, Gleckman 2019). 
Understanding the role of age inequities in American politics deserves more attention from political scientists than it has so far received, and in this paper, we carry out an exploratory analysis that moves that agenda forward. As theoretical motivation, we look to studies focused on senior citizens, particularly the argument that seniors' strong age identity and group cohesion have worked to increase their participation and influence in American politics (Anzia 2019, Campbell 2003). The general idea underlying this is an old one: some people with shared demographic characteristics remain a set of relatively unconnected individuals, whereas others are meaningful, connected groups whose shared identity has consequences for political participation (Arnold 1990, Campbell et al. 1960, 293). So far, however, this idea has not been deployed to explore patterns of turnout and representation across age groups. ${ }^{1}$

Do Americans feel a sense of group identity with others close to their age? If so, how does the average strength of that identity vary by age? And are people who feel stronger ties to others in their age group more likely to participate in politics? To explore these questions, we surveyed a representative sample of American adults to gauge how strongly they identify with others in their age group and to measure two forms of political participation: voting in national elections and engaging politically with climate change. Because measuring age identity is a new endeavor, we draw from established concepts and measures in the literature on social identity. Strong social or group identity (e.g., Tajfel 1981, Turner et al. 1987), meaning “an individual's awareness of belonging to a certain group and having a psychological attachment to that group" (McClain et al. 2009, 474), has been shown to be associated with higher rates of voting,

\footnotetext{
${ }^{1}$ In one promising new study, however, Munger and Plutzer (2020) explore people's willingness to vote for hypothetical candidates who advance older and younger generations' interests.
} 
contributing to campaigns, and political volunteering (e.g., Fowler and Kam 2007; Huddy 2013; Huddy and Khatib 2007). While social identity research is focused on identities such as race, political party, and nationality, we borrow measurement approaches from this literature to study the group identity of different age groups, and to explore the relationship between age identity and political participation.

We find that on average, younger adults have a weaker sense of age identity than senior citizens. However, for the youngest adults, age identity is as strong as political party identity. Moreover, age identity appears to be important for explaining patterns of political participation - more so for young adults than for older adults. And for climate action in particular, age identity is an especially strong predictor of participation for young Republicans. While our study is just an opening wedge, our hope is that it will inspire further research on age identity and, more broadly, age inequities in American politics.

\section{Measuring Age as a Group Identity}

The literature on social identity has not yet focused on age-based group identities, but it has developed measures of identity strength within other groups, such as those with shared nationality or party identification (Huddy and Khatib 2007, Theiss-Morse 2009). For example, in studying partisanship, Huddy, Mason, and Aarøe (2015) ask survey respondents a battery of questions and combine them into a multi-item partisan identity scale (see also Huddy and Bankert 2017). 
We use this same approach to measure age identity. In May 2020, we fielded a nationally-representative survey of 2,270 American adults. ${ }^{2}$ We pulled survey items from Huddy and Bankert's (2017) study of partisan identity and modified them to focus on age groups. Specifically, of the eight Likert items they employed, five could easily be adapted to ask about age groups:

- "I have a lot in common with other people my age."

- "I am interested in what other people think about my age group."

- "When others criticize people my age, it feels like a personal insult."

- "When others praise people my age, it makes me feel good."

- "When I meet someone my age, I feel connected with this person."

We measured respondents' agreement or disagreement with these statements on a five-point scale. ${ }^{3} \mathrm{We}$ then used factor analysis to combine the items into a single age identity strength variable and scaled it from 0 (weakest) to 1 (strongest). ${ }^{4}$

\footnotetext{
${ }^{2}$ We designed the survey to ensure a sample of young adults large enough to make comparisons across age groups. In the online appendix (A.1), we provide details about the survey instrument and sampling strategy.

${ }^{3}$ Individuals might think about their age and generational groups in different ways. Allowing respondents to define their "age group" as they see fit is appropriate for this exploratory research. ${ }^{4}$ For details, see the online appendix (A.2). We also adapted a widely-used measure of group consciousness from the race and ethnic politics literature—linked fate (e.g., Dawson 1994) - to age groups. See the online appendix (A.4). Because some scholars question the conceptual
} 
We begin by describing this age identity measure, first examining how the average varies across age groups, and then comparing it to partisan identity strength. Figure 1 presents average age identity by age (using a loess smoother). We find that average age group identity is similar for individuals between 20 and 55 years of age: the overall average for them is 0.54 on the 0 -to- 1 scale. Age identity is stronger, and increasing in age, for those over 55. For this group, the average is 0.59 - roughly a quarter of a standard deviation higher than the younger groups and a statistically significant difference $(\mathrm{p}<0.01$, two-tailed test). Therefore, our data suggest that older Americans have a stronger sense of age identity than younger Americans. ${ }^{5}$

clarity of the linked fate measure (Gay, Hochschild, and White 2016), we focus on age identity in our main analysis.

${ }^{5}$ Our results are robust to applying survey weights that match data to the 2016 American Community Survey (ACS). See online appendix (A.3). 
Figure 1: Average age group identity by age. We conduct a factor analysis of responses to five questions drawn from the social identity literature to measure age identity. Averages by age are generated using a loess smoother.

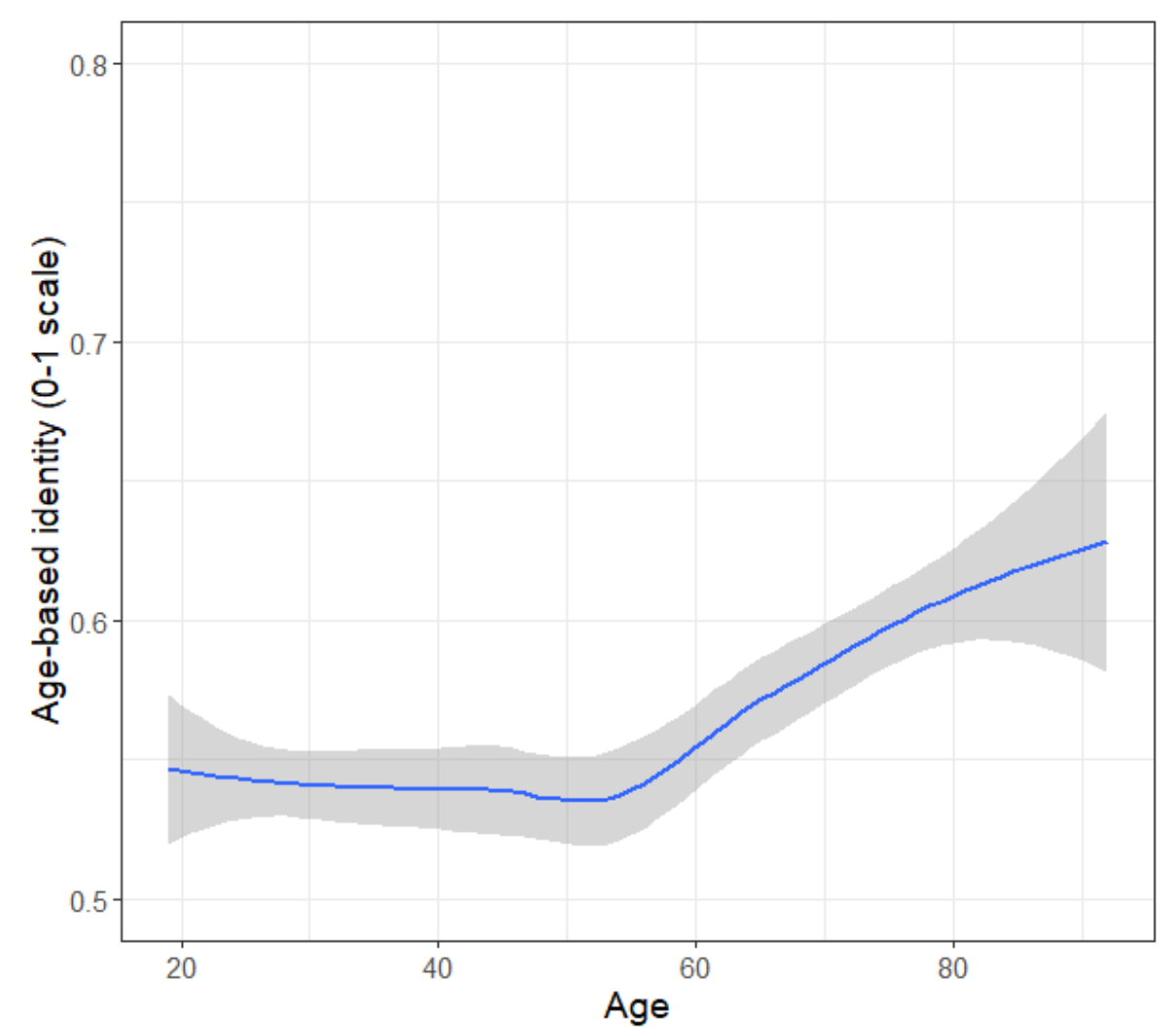

Next, in Figure 2, we compare age group identity to partisan identity — a useful benchmark given that it predicts political participation (Huddy, Mason, and Aarøe 2015). For respondents who affiliate with a political party (including those who lean toward a party), we asked the same five group identity questions listed above, using the original Huddy and Bankert (2017) partisan identity question wording. We then used a summated ratings scale (averaging across the items) to estimate 0 -to- 1 partisan identity and age identity measures for this group. ${ }^{6}$

\footnotetext{
${ }^{6}$ We use summated ratings scales here so that age and partisan identity are directly comparable.
} 
Figure 2: Comparing age identity to partisan identity. Restricting our sample to partisans and leaners, we estimate partisan identity and age identity by applying a summated ratings scale (simple average) to the same set of five questions. Averages by age are generated using a loess smoother.

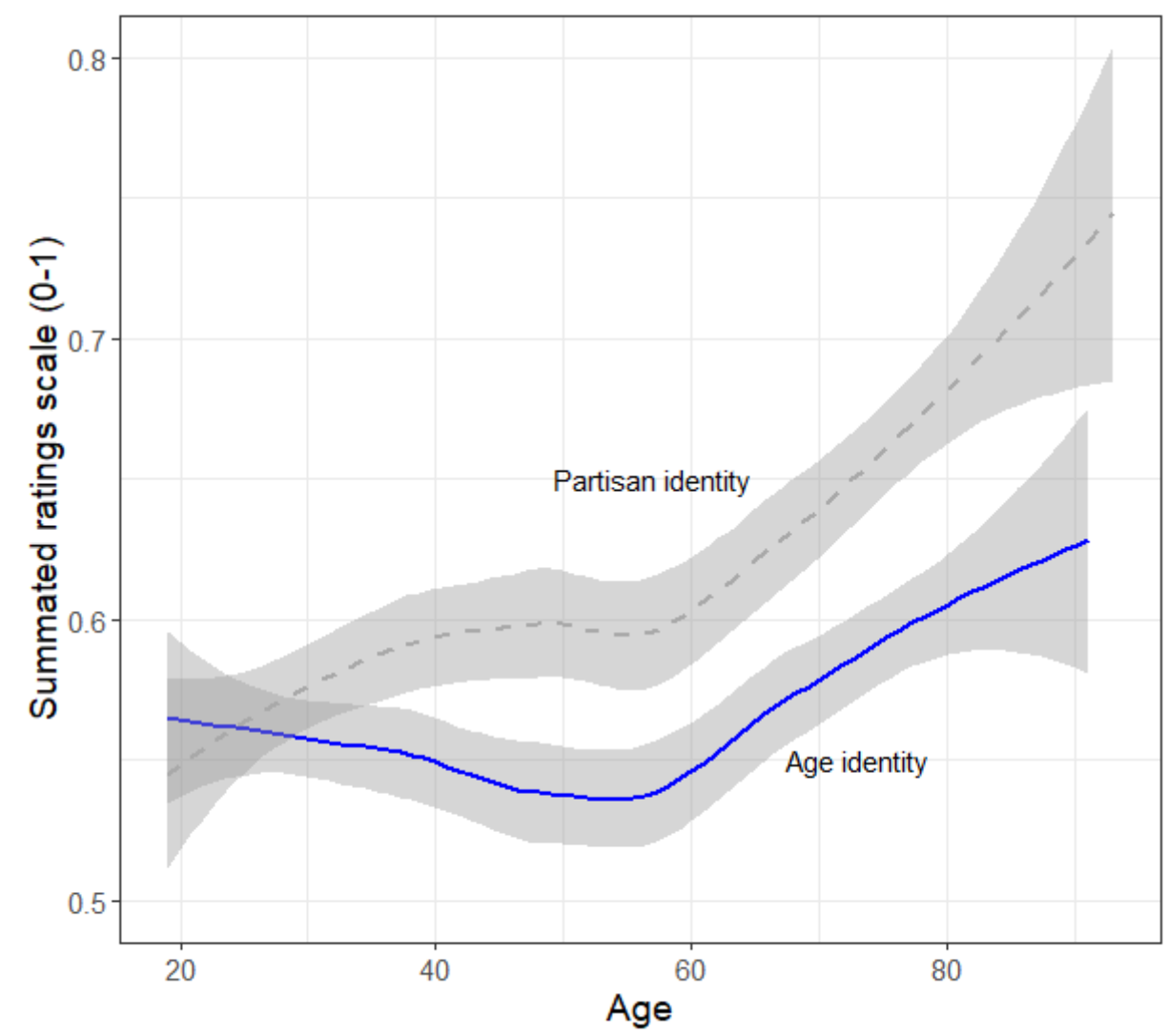

The figure shows that, in general (among partisans), partisan identity tends to be stronger than age identity. For young adults, however, the age identity and partisan identity averages are similar. This is notable because while American politics research emphasizes the importance of party identification and partisan identity, age group identity appears to be just as strong for young Americans.

\section{Age Identity and Political Participation}

We next examine whether individuals who feel stronger ties to others in their age group are more likely to participate in politics. Our first dependent variable is voter turnout: a binary 
indicator for whether the respondent reported having voted in the November 2018 election. $^{7}$ Turnout is a natural starting point, both because it is a commonly analyzed form of political participation, and because it is an important (and quantifiable) way for individuals to influence political outcomes.

However, voting is also a relatively blunt instrument for expressing political enthusiasm or policy demands. Protests and group activities can more precisely signal identification with a policy goal and may be more effective for raising the salience of an issue. Moreover, youth participate in some non-voting forms of political activity, such as protest, at relatively high rates (Norris 2011, Pew 2020, Strama 1998).

Thus, our second participation outcome measures participation in protests against inaction on climate change - an issue that stands to have disproportionately large consequences for today's youth. Consistent with popular perceptions that young people have been central to the rising climate change protest movement in recent years (Marris 2019), our data show that young Americans are more likely than their older counterparts to report having taken direct actions on climate change: $14 \%$ of those ages 20 to 29 and $16 \%$ of those ages 30 to 39 reported having joined a protest on climate change, compared to $3 \%$ of those over 50 .

To explore the relationship between age identity strength and participation, we estimate OLS models with age identity as the main independent variable and voting and climate protest activity as outcomes. The coefficients and standard errors are presented in Table 1.

\footnotetext{
${ }^{7}$ While over-reporting turnout merits concern (Berent et al. 2016), rates of over-reporting are not associated with age (Enamorado and Imai 2019), and it isn't clear how over-reporting would be associated with age identity strength.
} 
Column 1 presents the results of the bivariate model of voter turnout. Age identity is indeed a strong predictor of who turns out to vote. The coefficient estimate of 0.34 indicates that a one-standard-deviation increase in age identity ( 0.19 on a 0 -to- 1 scale) is associated with an increase in turnout of 6.5 percentage points on average.

In column 2, we add respondent age as an explanatory variable (scaled from 0 to 1 and centered around its mean), because age is positively correlated with turnout and - as shown in Figure 1 -age identity. We also interact respondent age with age identity to test whether the strength of the relationship between age identity and voting varies by age group. We find that it does. The negative and statistically significant coefficient on the interaction term shows that the relationship between age identity and turnout is decreasing with age. Moreover, when we add a set of other covariates associated with voting (column 3$),{ }^{8}$ this relationship persists. Thus, the degree to which an individual relates to others in her age group is a stronger predictor of turnout for young adults than for older adults.

In columns 4-6, we estimate the same models for climate change protest participation. In column 4, we once again find that age identity is positively associated with participation: a onestandard-deviation increase in age identity is associated with a 5 percentage-point increase in protest participation. As we discussed above, protest participation decreases with age; this is borne out in column 5 by the negative coefficient on age. However, in column 5 we also estimate a negative coefficient on the interaction term of age and age identity, and the same is true in

\footnotetext{
${ }^{8}$ We include seven-point party ID and indicators for race, gender, education (bachelor's degree), church attendance, and employment status. Full results are in the online appendix (A.3).
} 
column 6 when we add additional covariates. For climate protests as with voting, then, age identity is a stronger predictor of participation for younger adults than for older adults.

Table 1: Age identity is associated with political participation, but the relationship is decreasing in age.

\begin{tabular}{lcccccc}
\hline \hline & \multicolumn{3}{c}{ Voting } & \multicolumn{3}{c}{ Climate action } \\
& $(1)$ & $(2)$ & $(3)$ & $(4)$ & $(5)$ & $(6)$ \\
\hline Age identity & $0.34^{* *}$ & $0.21^{* *}$ & $0.17^{* *}$ & $0.29^{* *}$ & $0.30^{* *}$ & $0.28^{* *}$ \\
& $(0.05)$ & $(0.05)$ & $(0.05)$ & $(0.04)$ & $(0.03)$ & $(0.03)$ \\
Age & & $0.60^{* *}$ & $0.57^{* *}$ & & $-0.19^{* *}$ & $-0.18^{* *}$ \\
& & $(0.03)$ & $(0.03)$ & & $(0.02)$ & $(0.02)$ \\
Age identity * Age & & $-0.57^{* *}$ & $-0.45^{* *}$ & & $-0.66^{* *}$ & $-0.64^{* *}$ \\
& & $(0.17)$ & $(0.17)$ & & $(0.11)$ & $(0.11)$ \\
Covariates & No & No & Yes & No & No & Yes \\
\hline Observations & 2,183 & 2,183 & 2,183 & 2,176 & 2,176 & 2,176 \\
$\mathrm{R}^{2}$ & 0.02 & 0.14 & 0.22 & 0.04 & 0.09 & 0.10 \\
\hline \hline
\end{tabular}

Note: Robust standard errors in parentheses. ${ }^{* *} \mathrm{p}<.01$.

To further illustrate how the relationship between age identity and political participation varies by age, we split the sample by 10-year age intervals and regress both voter turnout and climate protest on age identity for each group. The coefficient estimates are presented in Figure 3. ${ }^{9}$ For both voter turnout (on the left) and climate protest (on the right), the estimated coefficients on age identity are larger for younger Americans than for older Americans. For respondents aged 20 to 49 , age identity has a positive, statistically significant relationship with voting, but for the 50-and-older age groups, the coefficients are smaller and insignificant at the $5 \%$ level. Moreover, the association between age identity and climate protest is relatively large

\footnotetext{
${ }^{9}$ We present the estimates from bivariate models, but as we show in the online appendix (A.3), the results are similar when we include covariates.
} 
for 20-to-39-year olds but smaller for those 40-and-older - and statistically insignificant for the oldest groups of citizens.

Figure 3: The relationship between age identity and political participation is driven by younger adults. Points represent coefficients from bivariate OLS regression, with age identity as the independent variable. Lines are 95 percent confidence intervals.
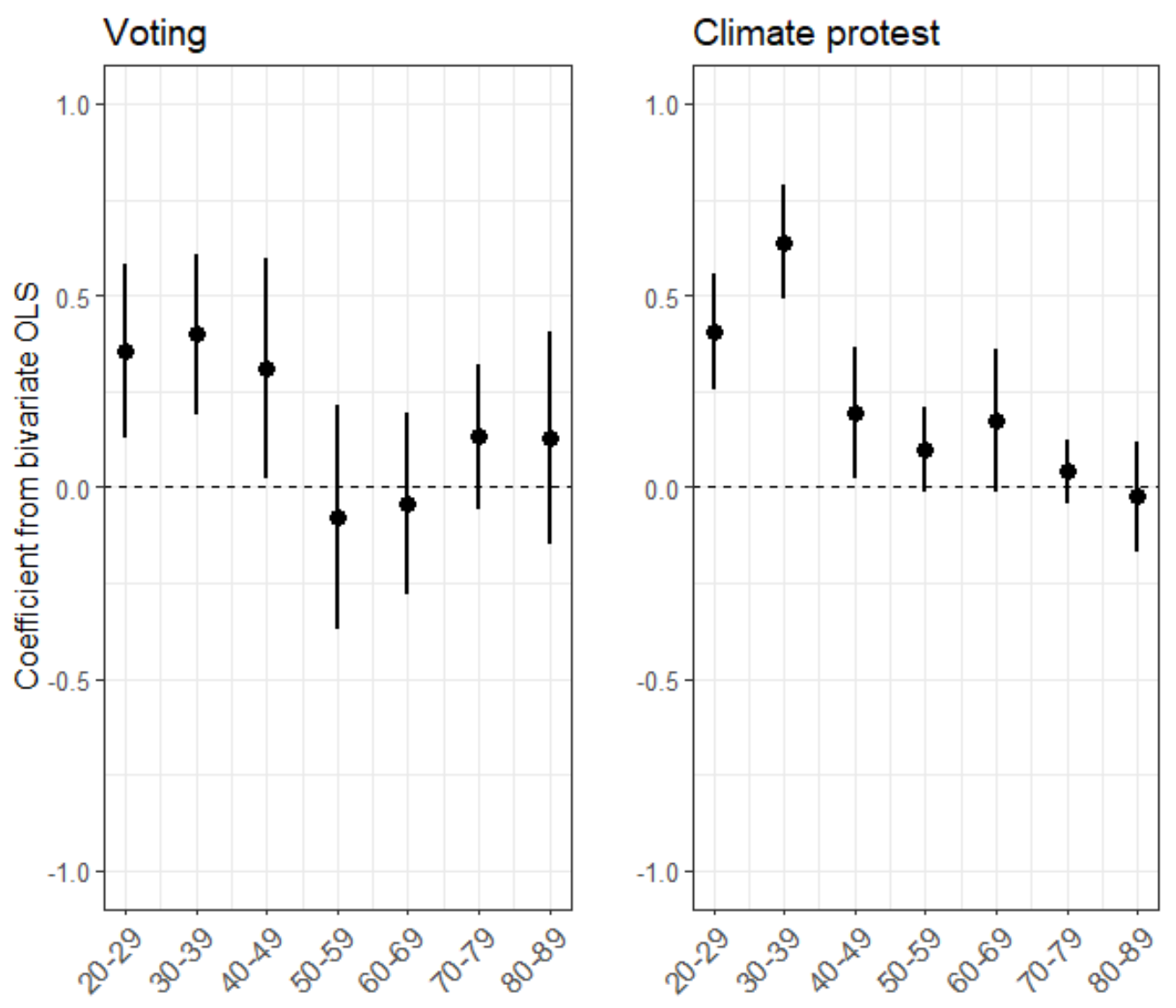

For climate action, it is also important to assess how these relationships vary by party identification. Public opinion on matters related to climate change varies by party identification (Carmichael et al. 2017), and in our data, Democrats are more likely than Independents or Republicans to report having attended climate change protests. The difference in participation by party is especially pronounced among older voters, with older Democrats greatly outpacing older Republicans. This accords with journalistic accounts of young Republicans deviating from their 
older co-partisans in prioritizing climate change (e.g., Brady 2020). One possible explanation for this relatively high rate of participation among young Republicans is that they identify with others in their age group.

In Figure 4, we assess whether the relationship between age identity and climate action varies by party identification within age groups. We subset the data into 10-year age groups and by party identification, and estimate bivariate OLS models within each subset. ${ }^{10}$ For the older groups, the relationships between age identity and climate action are small, statistically insignificant, and do not differ clearly by party. For the younger groups, however, the findings are striking: the positive relationship between age identity and climate action appears to be driven more by young Republicans than young Democrats or Independents. Among those in the 20-to-29 and 30-to-39 age groups, the association between age identity and climate action is larger for Republicans than for Democrats. ${ }^{11}$ This partisan gap is especially large for the 20-to29 group. This suggests that age identity is not only an important motivator of political participation among young people, but that it also has potential to cross-cut political party affiliation — which would have significant implications for the politics of climate change.

${ }^{10}$ Our sample includes 254 Republican respondents under age 40 (11 percent of our sample). ${ }^{11}$ Among respondents under 40, 16\% of Democrats reported participating in climate action, compared to $19 \%$ of Republicans. (These numbers include individuals who lean toward one party or the other.) 
Figure 4: The relationship between age identity and participation in climate protest is driven by young Republicans. Points represent coefficients from bivariate OLS regression, with participation in climate protest as the outcome and age identity as the independent variable. Lines are 95 percent confidence intervals. Estimates are not presented for older independents and Republicans due to lack of respondents participating in protests.

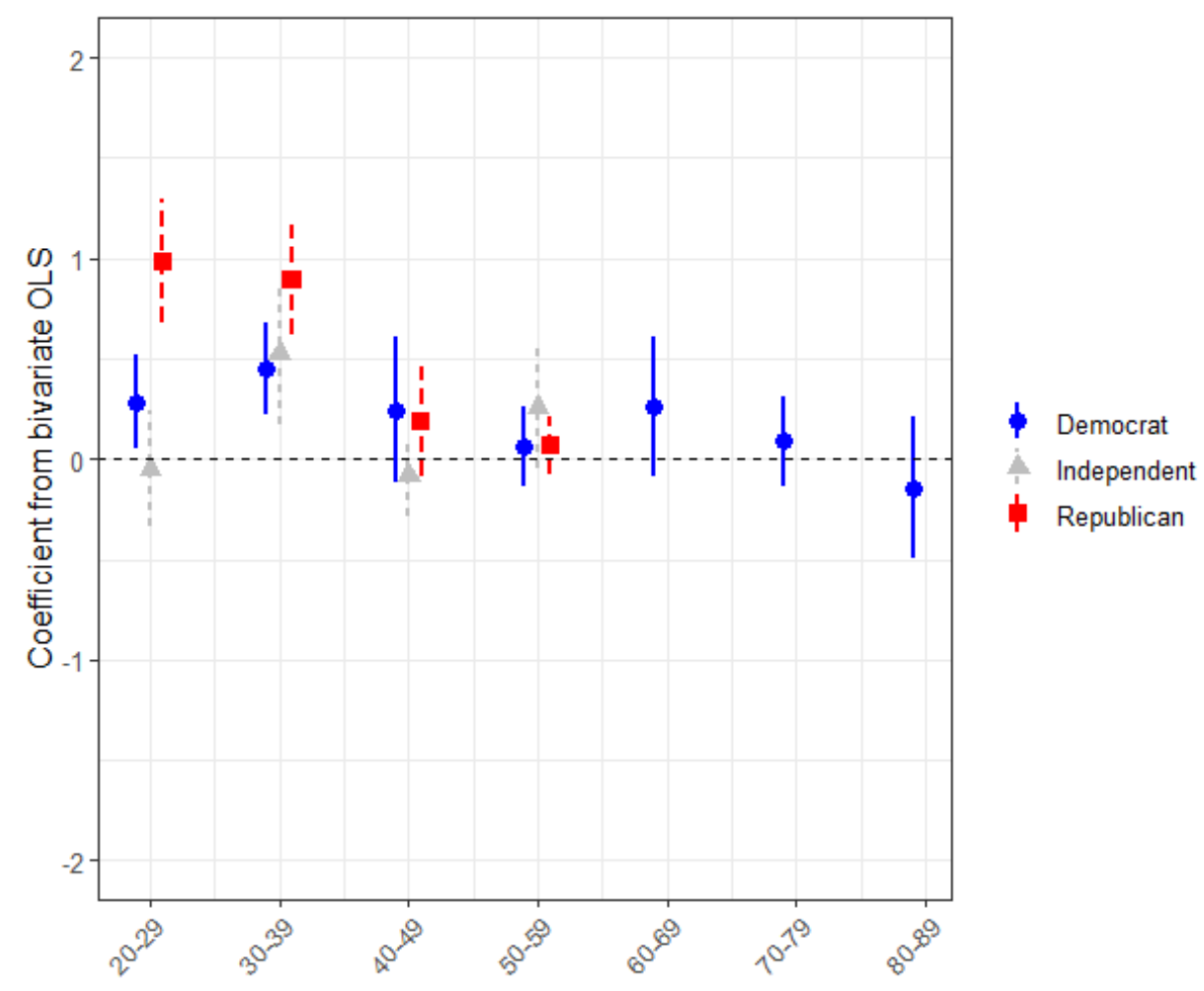

\section{Conclusion}

There is growing recognition that age matters for American politics. Public preferences on salient issues like policing and climate change differ by age (Goldstein 2019). Younger generations will likely bear the brunt of problems ranging from climate change to housing to the solvency of Social Security. Perhaps in part because of this, youth voting rates increased in the 2018 and 2020 national elections. Some credit the tipping of the scales to the Democratic ticket in Georgia in November 2020 and January 2021 to the increased engagement of young voters (Rojas 2021). For scholarly political science research, an increased focus on age, youth, and political participation is long overdue. 
We have aimed to make progress in this area by tapping into general arguments from the identity literature about how groups of citizens vary in their cohesion, and about how individuals with a stronger sense of group identity often participate in politics at higher rates. Applying measures from this literature to age, we find that younger voters do have a weaker sense of age group identity compared to senior citizens. But there is variation in how strongly people associate with others their age, and that variation matters-especially for young people. Among younger Americans in particular, individuals with stronger age identity are significantly more likely to vote and participate in protests related to climate change. For climate protests, age identity is more important for young Republicans than young Democrats. Thus, there seems to be potential for a bipartisan coalition of young people active on the issue of climate change, possibly driven in part by their shared age identity.

Our analysis is merely an opening wedge, but an important one that suggests several promising directions for future research. Scholars should continue to refine the definition and operationalization of age identity and prioritize it as a potentially important group identity in American politics. Researchers should explore the conditions that enhance or detract from age identity. Are there certain issues that augment citizens' feelings of connection to others in their age group? Are there particular policies—such as student loan forgiveness, gun safety, or housing development reform — that help to make young people a more meaningful political group, as Campbell (2003) found for Social Security and senior citizens? Perhaps most importantly, researchers should further study the consequences of age identity for political behavior, political outcomes, and public policy. 


\section{References}

Anzia, Sarah F. 2019. "When Does a Group of Citizens Influence Policy? Evidence from Senior Citizen Participation in City Politics.” Journal of Politics 81(1): 1-14.

—. Forthcoming. "Pensions in the Trenches: How Pension Spending is Affecting U.S. Local Government." Urban Affairs Review.

Arnold, R. Douglas. 1990. The Logic of Congressional Action. Yale University Press. http://www.jstor.org/stable/j.ctt32bm5b.

Beck, Paul Allen, and M. Kent Jennings. 1982. "Pathways to Participation.” The American Political Science Review 76(1): 94-108.

Berent, Matthew K, Jon A Krosnick, and Arthur Lupia. 2016. “Measuring Voter Registration and Turnout in Surveys." Public Opinion Quarterly 80(3): 597-621.

Brady, Jeff. 2020. “'Light Years Ahead’ Of Their Elders, Young Republicans Push GOP On Climate Change." NPR. https://www.npr.org/2020/09/25/916238283/light-years-aheadof-their-elders-young-republicans-push-gop-on-climate-change.

Campbell, Andrea Louise. 2003. How Policies Make Citizens: Senior Political Activism and the American Welfare State. Princeton University Press.

Campbell, Angus, P.E. Converse, W. E. Miller, and D. E. Stokes. 1960. The American

Voter. Unabridged ed. Chicago [Ill.]: University of Chicago Press.

Carmichael, Jason T., Robert J. Brulle, and Joanna K. Huxster. 2017. “The Great Divide:

Understanding the Role of Media and Other Drivers of the Partisan Divide in Public Concern over Climate Change in the USA, 2001-2014." Climatic Change 141(4): 599612.

Congressional Budget Office. 2000. "Federal Spending on the Elderly and Children.” CBO Report, July 27, 2000. https://www.cbo.gov/publication/12534 
Dawson, Michael C. 1994. Behind the Mule: Race and Class in African-American Politics. Princeton University Press.

Einstein, Katherine Levine, David M. Glick, and Maxwell Palmer. 2019. Neighborhood Defenders. New York: Cambridge University Press.

Enamorado, Ted, and Kosuke Imai. 2019. "Validating Self-Reported Turnout by Linking Public Opinion Surveys with Administrative Records." Public Opinion Quarterly 83(4): 723-48.

Fowler, James H., and Cindy D. Kam. 2007. "Beyond the Self: Social Identity, Altruism, and Political Participation." The Journal of Politics 69(3): 813-27.

Gay, Claudine, Jennifer Hochschild, and Ariel White. 2016. “Americans’ Belief in Linked Fate: Does the Measure Capture the Concept?" The Journal of Race, Ethnicity, and Politics 1(1): 117-44.

Gleckman, Howard. 2019. "The Federal Government Will Spend Half its Budget on Older Americans in Ten Years.” Forbes, February 1.

https://www.forbes.com/sites/howardgleckman/2019/02/01/the-federal-governmentwill-spend-half-its-budget-on-older-adults-in-ten-years/?sh=7b998fe556b6

Goldstein, Rebecca. 2019. "The Age of Police Reform.” University of California, Berkeley, working paper.

Grumbach, Jacob M., and Charlotte Hill. Forthcoming. "Rock the Registration: Same Day Registration Increases Turnout of Young Voters.” Journal of Politics.

Hill, Charlotte. 2020. "Young People Face Higher Voting Costs and Are Less Informed About State Voting Laws.” Berkeley Institute for Young Americans.

http://youngamericans.berkeley.edu/wp- 
content/uploads/2020/08/Hill BIFYA Working Paper 0808 2020.pdf.

Holbein, John B., and D. Sunshine Hillygus. 2020. Making Young Voters: Converting Civic Attitudes Into Civic Action. Cambridge University Press.

Huddy, Leonie. 2013. From Group Identity to Political Cohesion and Commitment. Oxford University Press.

Huddy, Leonie, and Alexa Bankert. 2017. "Political Partisanship as a Social Identity." Oxford Research Encyclopedia of Politics.

https://oxfordre.com/politics/politics/politics/view/10.1093/acrefore/9780190228637.00 1.0001/acrefore-9780190228637-e-250.

Huddy, Leonie, and Nadia Khatib. 2007. "American Patriotism, National Identity, and Political Involvement.” American Journal of Political Science 51(1): 63-77.

Huddy, Leonie, Lilliana Mason, and Lene Aarøe. 2015. "Expressive Partisanship: Campaign Involvement, Political Emotion, and Partisan Identity.” American Political Science Review 109(1): 1-17.

Marris, Emma. 2019. “Why Young Climate Activists Have Captured the World's Attention." Nature 573(7775): 471+.

McClain, Paula D., Jessica D. Johnson Carew, Eugene Walton, and Candis S. Watts. 2009. “Group Membership, Group Identity, and Group Consciousness: Measures of Racial Identity in American Politics?” Annual Review of Political Science 12(1): 471-85.

Munger, Kevin, and Eric Plutzer. 2020. "Generations in Contemporary American Politics: Statistical Aggregations or Collective Political Actors?” Penn State University Working Paper.

Noah, Timothy. 2019. “America, the Gerontocracy.” Politico, September 3. 
https://www.politico.com/magazine/story/2019/09/03/america-gerontocracy-problempolitics-old-politicians-trump-biden-sanders-227986

Norris, Pippa. 2011. Democratic Deficit: Critical Citizens Revisited. New York: Cambridge University Press.

Pew Research Center. 2020. "Recent Protest Attendees Are More Racially and Ethnically Diverse, Younger than Americans Overall.” Pew Research Center. https://www.pewresearch.org/fact-tank/2020/06/24/recent-protest-attendees-are-moreracially-and-ethnically-diverse-younger-than-americans-overall/.

Rojas, Rick. 2021. "Phone Calls, Texts and Tinder: Georgia Campaigns Court Young Voters." New York Times. https://www.nytimes.com/2021/01/04/us/georgia-runoffyoung-voters.html.

Rosenstone, Steven J, and John Mark Hansen. 1993. Mobilization, Participation, and Democracy in America. New York: Longman.

Strama, Mark. 1998. "Overcoming Cynicism: Youth Participation and Electoral Politics." National Civic Review 87(1): 71-78.

Strate, John M., Charles J. Parrish, Charles D. Elder, and Coit Ford. 1989. "Life Span Civic Development and Voting Participation." American Political Science Review 83(2): $443-64$.

Tajfel, Henri. 1981. Human Groups and Social Categories: Studies in Social Psychology. Cambridge: Cambridge University Press.

Theiss-Morse, Elizabeth. 2009. Who Counts as an American?: The Boundaries of National Identity. Cambridge University Press.

Turner, John C. et al. 1987. Rediscovering the Social Group: A Self-Categorization Theory. 
Basil Blackwell.

Verba, Sidney, and Norman H. Nie. 1987. Participation in America: Political Democracy and Social Equality. University of Chicago Press ed. Chicago: University of Chicago Press.

Verba, Sidney, Kay Lehman Schlozman, and Henry E. Brady. 1995. Voice and Equality: Civic Voluntarism in American Politics. Cambridge, Mass: Harvard University Press.

Wolfinger, Raymond E, and Rosenstone, Steven J. 1980. Who Votes? New Haven: Yale University Press. 


\title{
Age Group Identity and Political Participation \\ Online Appendix
}

\author{
Samuel Trachtman, UC Berkeley \\ Sarah F. Anzia, UC Berkeley \\ Charlotte Hill, UC Berkeley
}

\begin{abstract}
A.1 Sampling and survey instrument
In May, 2020, YouGov interviewed 2448 respondents who were then matched down to a sample of 2270 to produce the dataset. Respondents were matched to a sampling frame constructed by stratified sampling from the 2016 American Community Survey (ACS) 1-year sample by gender, age, race, and education. We over-sampled young adults (those aged 18-39) to increase statistical power for across-age comparisons.

The survey had several modules, one of which focused specifically on age identity and political participation. We provide details on the battery of questions used to measure age identity in the main text. Our main political participation outcomes are turnout and climate protests. For turnout, we asked: "Did you vote in the 2018 election." For climate protests, we asked: "Have you joined a march or protest about climate change?"
\end{abstract}

\section{A.2 Factor analysis details}

We conduct exploratory factor analysis (EFA) to estimate age identity scores using a battery of five questions drawn from existing literature measuring partisan identity. The questions are:

- "I have a lot in common with other people my age."

- "I am interested in what other people think about my age group."

- "When others criticize people my age, it feels like a personal insult."

- "When others praise people my age, it makes me feel good."

- "When I meet someone my age, I feel connected with this person."

Each of the five tests run using the $n$ Factors package in $\mathrm{R}$ indicated that retaining a single factor was appropriate. All 5 of the items in the age identity battery loaded positively onto the common factor (as demonstrated in Table A1). The common factor explained 42 percent of the variation across the five items. 


\section{Table A1: Factor loadings}

\begin{tabular}{lc}
\hline \hline & Common factor \\
\hline Common & 0.63 \\
Interested & 0.64 \\
Insult & 0.53 \\
Praise & 0.71 \\
Connected & 0.73 \\
\hline
\end{tabular}

A.3 Robustness checks and full results

Figure A1: Age group identity by age, with survey weights. Points represent average age identity for each age group. We apply survey weights generated by matching respondents to a stratified sample from the 2016 American Community Survey. Lines represent 95 percent confidence intervals.

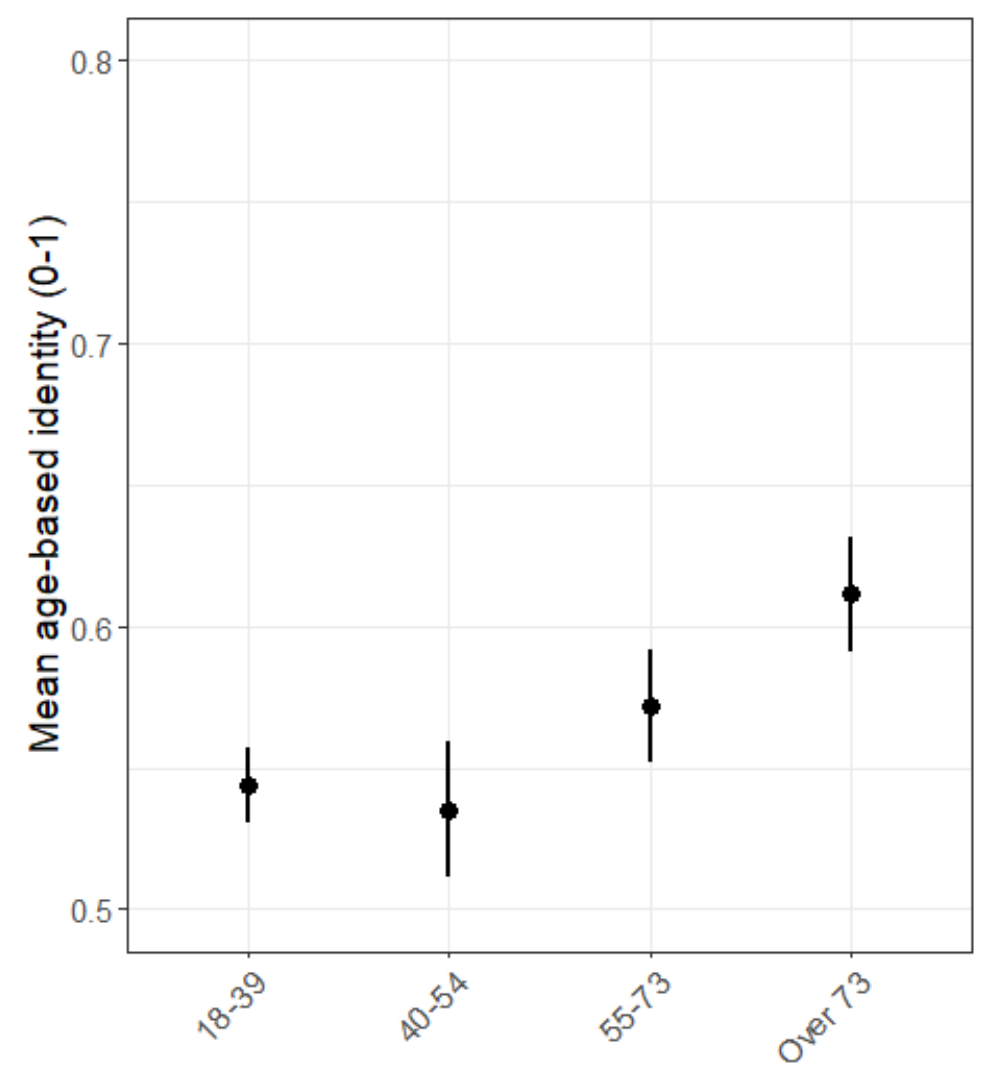


Table A2: Age identity is associated with political participation, but the relationship is decreasing in age (full estimates).

\begin{tabular}{|c|c|c|c|c|c|c|}
\hline & \multicolumn{3}{|c|}{ Voting } & \multicolumn{3}{|c|}{ Climate action } \\
\hline & $(1)$ & $(2)$ & $(3)$ & $(4)$ & $(5)$ & $(6)$ \\
\hline Age identity & $\begin{array}{c}0.34^{* * *} \\
(0.05)\end{array}$ & $\begin{array}{c}0.21^{* * *} \\
(0.05)\end{array}$ & $\begin{array}{c}0.17^{* * *} \\
(0.05)\end{array}$ & $\begin{array}{c}0.29^{* * *} \\
(0.04)\end{array}$ & $\begin{array}{c}0.30^{* * *} \\
(0.03)\end{array}$ & $\begin{array}{c}0.28^{* * *} \\
(0.03)\end{array}$ \\
\hline Age & & $\begin{array}{c}0.60^{* * *} \\
(0.03)\end{array}$ & $\begin{array}{c}0.57^{* * *} \\
(0.03)\end{array}$ & & $\begin{array}{c}-0.19^{* * *} \\
(0.02)\end{array}$ & $\begin{array}{c}-0.18^{* * *} \\
(0.02)\end{array}$ \\
\hline Age identity ${ }^{*}$ Age & & $\begin{array}{c}-0.57^{* * *} \\
(0.17)\end{array}$ & $\begin{array}{c}-0.45^{* * *} \\
(0.17)\end{array}$ & & $\begin{array}{c}-0.66^{* * *} \\
(0.11)\end{array}$ & $\begin{array}{c}-0.64^{* * *} \\
(0.11)\end{array}$ \\
\hline PID & & & $\begin{array}{c}-0.02^{* * *} \\
(0.004)\end{array}$ & & & $\begin{array}{l}-0.005 \\
(0.003)\end{array}$ \\
\hline White & & & $\begin{array}{c}0.08^{* * *} \\
(0.02)\end{array}$ & & & $\begin{array}{l}-0.03 \\
(0.02)\end{array}$ \\
\hline Black & & & $\begin{array}{c}0.04 \\
(0.04)\end{array}$ & & & $\begin{array}{l}-0.01 \\
(0.02)\end{array}$ \\
\hline Male & & & $\begin{array}{c}0.11^{* * *} \\
(0.02)\end{array}$ & & & $\begin{array}{c}0.02 \\
(0.01)\end{array}$ \\
\hline Bachelors degree & & & $\begin{array}{c}0.16^{* * *} \\
(0.02)\end{array}$ & & & $\begin{array}{l}0.02^{*} \\
(0.01)\end{array}$ \\
\hline Church-going & & & $\begin{array}{l}0.04^{* *} \\
(0.02)\end{array}$ & & & $\begin{array}{l}0.03^{* *} \\
(0.01)\end{array}$ \\
\hline Out of work & & & $\begin{array}{c}-0.12^{* * *} \\
(0.03) \\
\end{array}$ & & & $\begin{array}{l}-0.01 \\
(0.02) \\
\end{array}$ \\
\hline Observations & 2,183 & 2,183 & 2,183 & 2,176 & 2,176 & 2,176 \\
\hline $\mathrm{R}^{2}$ & 0.02 & 0.14 & 0.22 & 0.04 & 0.09 & 0.10 \\
\hline
\end{tabular}

Note: Estimates are generated using ordinary least squares regression. Robust standard errors in parentheses. ${ }^{*} \mathrm{p}<.1 ; * * \mathrm{p}<.05 ; * * * \mathrm{p}<.01$. 
Figure A2: The relationship between age identity and political participation is stronger for younger adults (estimates from models with covariates). Points represent coefficients from OLS regression with age identity as the independent variable and the following covariates: the standard seven-point party ID scale and indicators for race, gender, education (bachelor's degree), regular church attendance, and employment status. Lines are 95 percent confidence intervals.
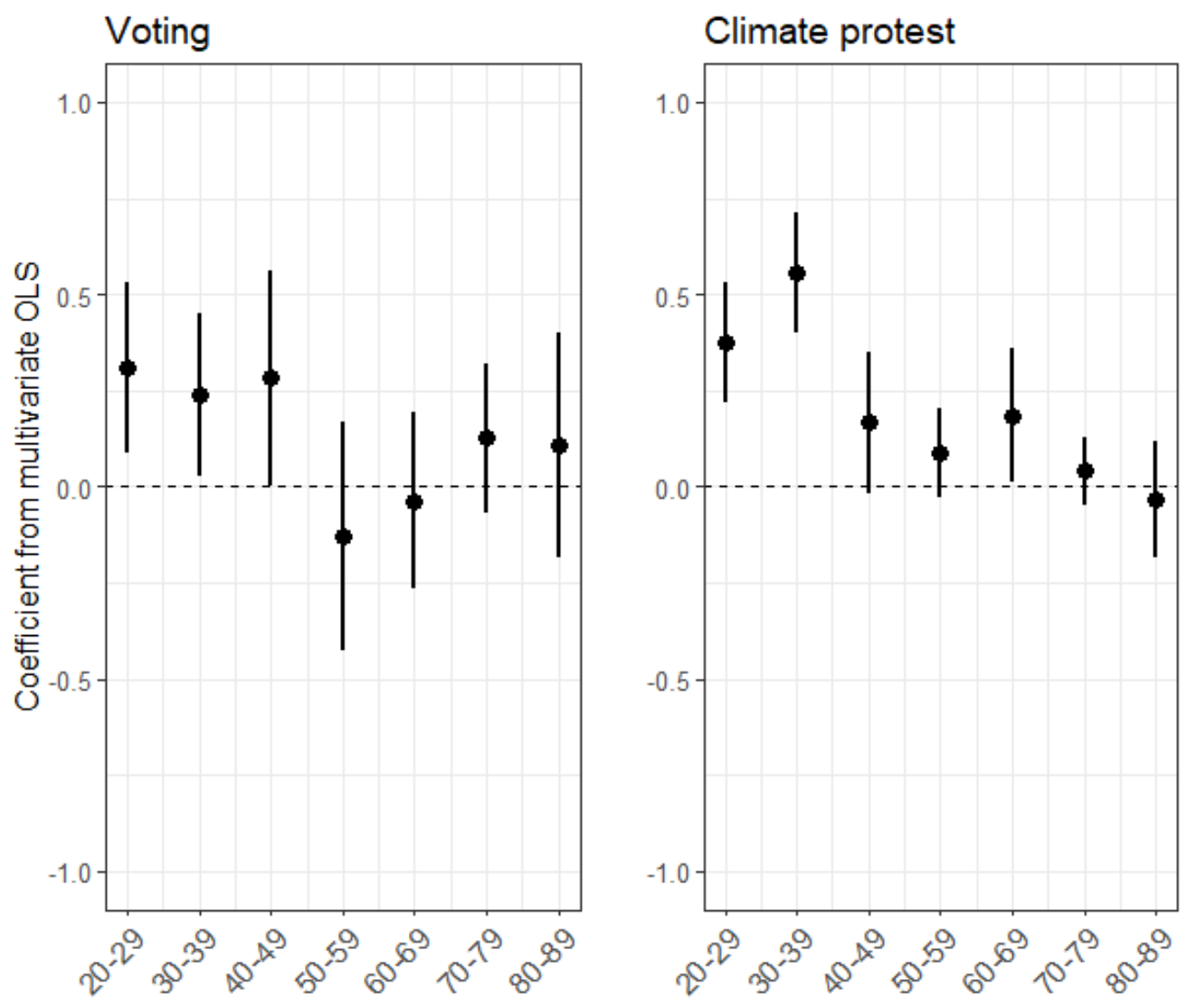


\section{A.4 Linked fate}

Figure A3: Linked fate estimates by age. We use a standard linked fate battery but applied to age groups. We first asked respondents: "Do you think what happens to other people in your age group in this country will have something to do with what happens in your life?" Respondents could answer yes or no. A measure of 0 is applied to those who responded "no." For those who answered "yes," we asked: "How much will it affect you?" Respondents are scored 1-3 based on whether they chose "Not very much at all", "Some", or "A lot."

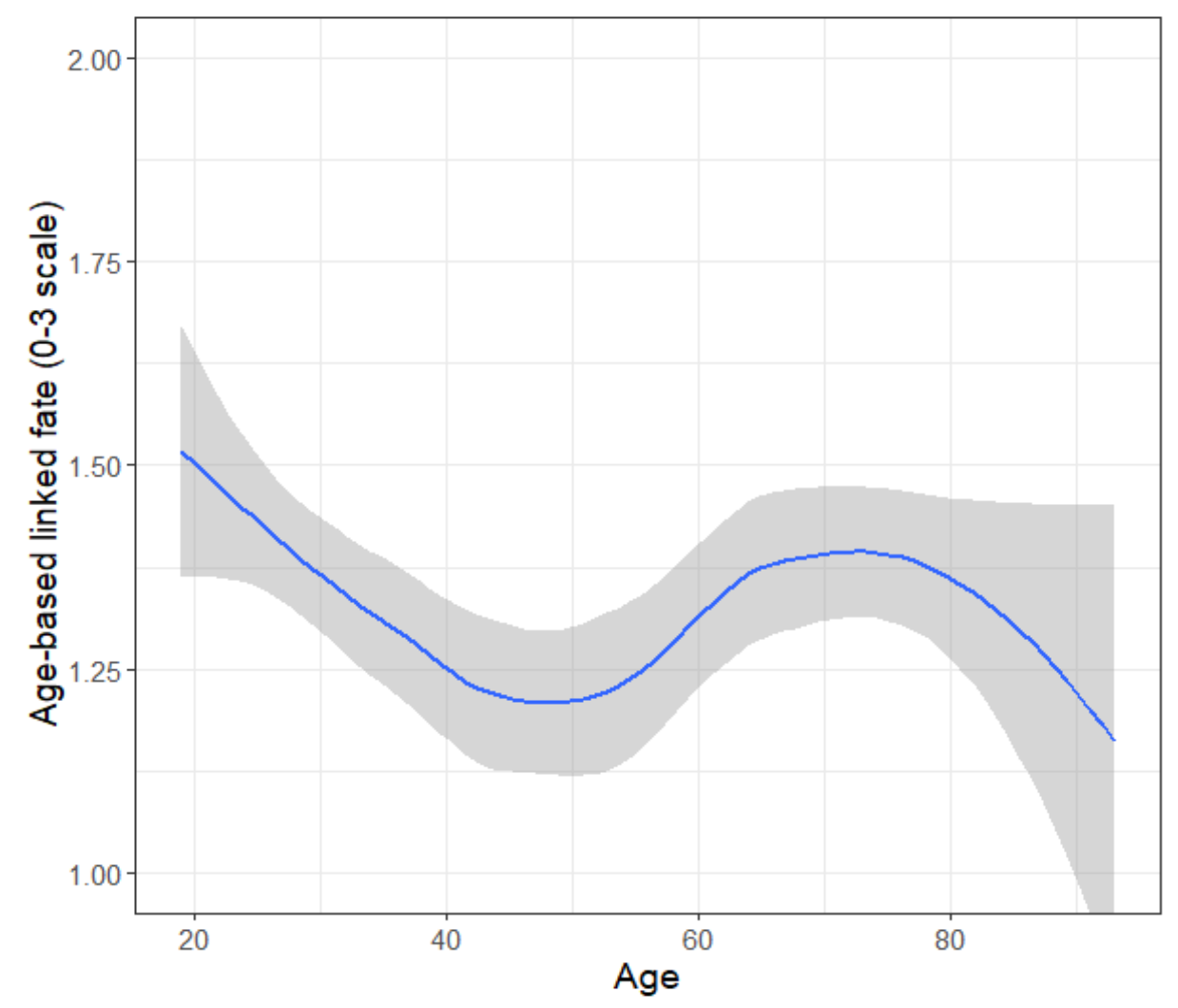


Table A3: Age linked fate is associated with political participation, but the relationship is decreasing in age.

\begin{tabular}{|c|c|c|c|c|c|c|}
\hline & \multicolumn{3}{|c|}{ Voting } & \multicolumn{3}{|c|}{ Climate action } \\
\hline & $(1)$ & $(2)$ & $(3)$ & $(4)$ & $(5)$ & $(6)$ \\
\hline Age linked fate & $\begin{array}{c}0.05^{* * *} \\
(0.01)\end{array}$ & $\begin{array}{c}0.05^{* * *} \\
(0.01)\end{array}$ & $\begin{array}{c}0.03^{* * *} \\
(0.01)\end{array}$ & $\begin{array}{c}0.03^{* * *} \\
(0.01)\end{array}$ & $\begin{array}{l}0.03^{* * *} \\
(0.005)\end{array}$ & $\begin{array}{c}0.03^{* * *} \\
(0.01)\end{array}$ \\
\hline Age & & $\begin{array}{c}0.78^{* * *} \\
(0.05)\end{array}$ & $\begin{array}{c}0.74^{* * *} \\
(0.05)\end{array}$ & & $\begin{array}{c}-0.11^{* * *} \\
(0.03)\end{array}$ & $\begin{array}{c}-0.10^{* * *} \\
(0.03)\end{array}$ \\
\hline Age linked fate ${ }^{*}$ Age & & $\begin{array}{c}-0.13^{* * *} \\
(0.03)\end{array}$ & $\begin{array}{c}-0.12^{* * *} \\
(0.03)\end{array}$ & & $\begin{array}{c}-0.05^{* * *} \\
(0.02)\end{array}$ & $\begin{array}{c}-0.05^{* * *} \\
(0.02)\end{array}$ \\
\hline PID & & & $\begin{array}{c}-0.02^{* * *} \\
(0.004)\end{array}$ & & & $\begin{array}{l}-0.01^{*} \\
(0.003)\end{array}$ \\
\hline White & & & $\begin{array}{c}0.08^{* * *} \\
(0.02)\end{array}$ & & & $\begin{array}{c}-0.03^{* *} \\
(0.02)\end{array}$ \\
\hline Black & & & $\begin{array}{c}0.05 \\
(0.03)\end{array}$ & & & $\begin{array}{l}-0.01 \\
(0.02)\end{array}$ \\
\hline Male & & & $\begin{array}{c}0.11^{* * *} \\
(0.02)\end{array}$ & & & $\begin{array}{c}0.02 \\
(0.01)\end{array}$ \\
\hline Bachelors degree & & & $\begin{array}{c}0.16^{* * *} \\
(0.02)\end{array}$ & & & $\begin{array}{c}0.02 \\
(0.01)\end{array}$ \\
\hline Church-going & & & $\begin{array}{c}0.05^{* * *} \\
(0.02)\end{array}$ & & & $\begin{array}{c}0.05^{* * *} \\
(0.01)\end{array}$ \\
\hline Out of work & & & $\begin{array}{c}-0.11^{* * *} \\
(0.03) \\
\end{array}$ & & & $\begin{array}{l}-0.01 \\
(0.02) \\
\end{array}$ \\
\hline Observations & 2,266 & 2,266 & 2,266 & 2,255 & 2,255 & 2,255 \\
\hline $\mathrm{R}^{2}$ & 0.02 & 0.16 & 0.23 & 0.02 & 0.05 & 0.06 \\
\hline
\end{tabular}

Note: Estimates are generated using ordinary least squares regression. Robust standard errors in parentheses. ${ }^{*} \mathrm{p}<.1 ; * * \mathrm{p}<.05 ; * * * \mathrm{p}<.01$. 
Figure A4: The relationship between age linked fate and political participation is stronger for younger adults. Points represent coefficients from bivariate OLS regression, with age linked fate as the independent variable. Lines are 95 percent confidence intervals.
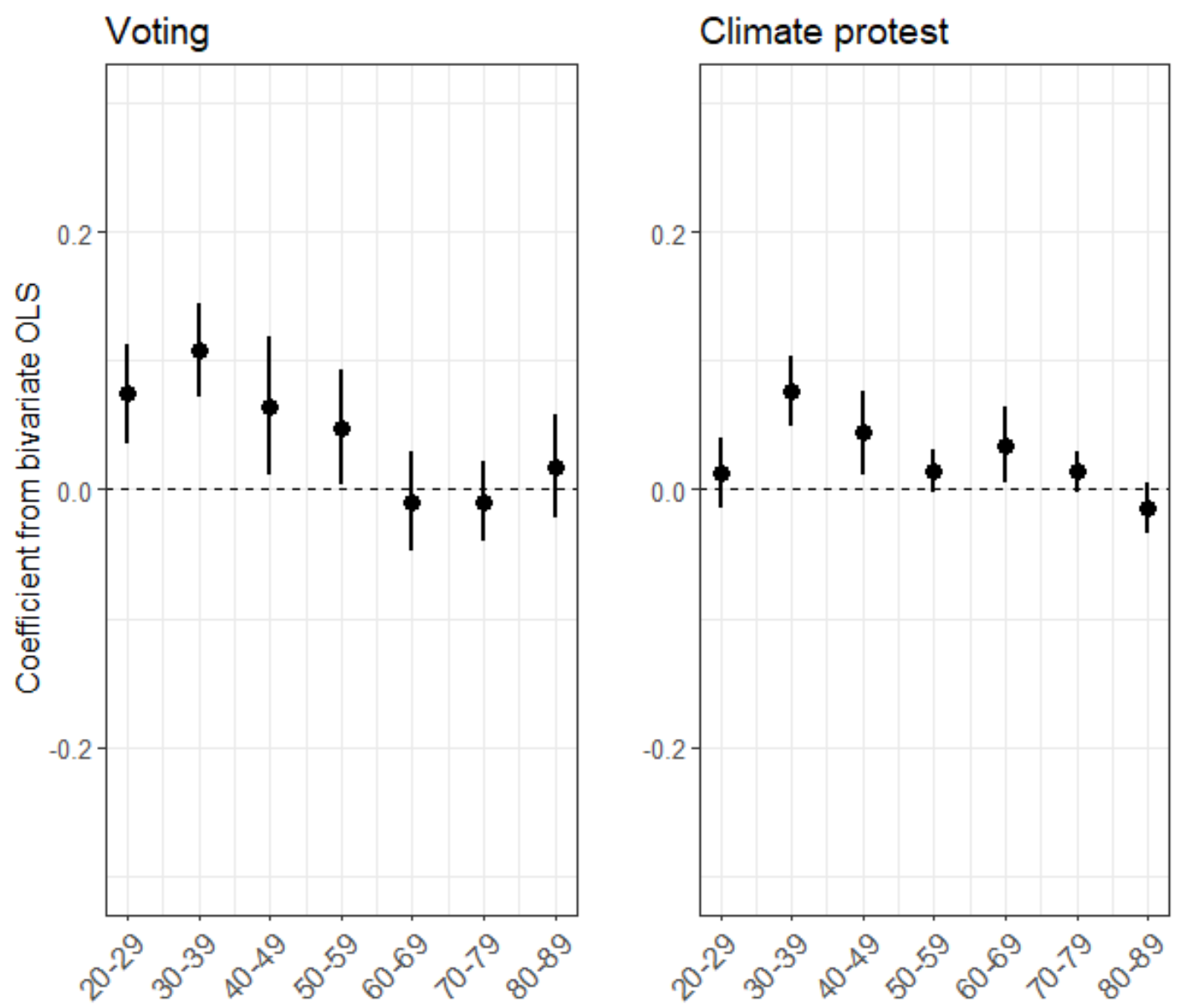